\title{
High blood pressure, a red flag for the neonatal manifestation of urea cycle disorders
}

\author{
Ulrike Teufel ${ }^{1,2^{*}}$, Peter Burgard ${ }^{1}$, Jochen Meyburg ${ }^{1}$, Martin Lindner ${ }^{3}$, Johannes Poeschl ${ }^{4}$, Peter Ruef ${ }^{5}$, \\ Georg F. Hoffmann ${ }^{1}$ and Stefan Kölker ${ }^{1}$
}

\begin{abstract}
Background: Neonatal manifestation of life-threatening hyperammonemic encephalopathy in urea cycle disorders (UCD) is often misdiagnosed as neonatal sepsis, resulting in significantly delayed start of specific treatment and poor outcome. The major aim of this study was to identify specific initial symptoms or signs to clinically distinguish hyperammonemic encephalopathy in neonates from neonatal sepsis in order to identify affected individuals with UCD and to start metabolic therapy without delay. Furthermore, we evaluated the impact of diagnostic delay, peak plasma ammonium $\left(\mathrm{NH}_{4}{ }^{+}\right)$concentration, mode of emergency treatment and transfer to a tertiary referral center on the outcome.
\end{abstract}

Methods: Detailed information of 17 patients (born between 1994 and 2012) with confirmed diagnosis of UCD and neonatal hyperammonemic encephalopathy were collected from the original medical records.

Results: The initially suspected diagnosis was neonatal sepsis in all patients, but was not confirmed in any of them. Unlike neonatal sepsis and not previously reported blood pressure increased above the 95th percentile in 13 (81\%) of UCD patients before emergency treatment was started. Respiratory alkalosis was found in 11 (65\%) of UCD patients, and in 14 (81\%) plasma $\mathrm{NH}_{4}{ }^{+}$concentrations further increased despite initiation of metabolic therapy.

Conclusion: Detection of high blood pressure could be a valuable parameter for distinguishing neonatal sepsis from neonatal manifestation of UCD. Since high blood pressure is not typical for neonatal sepsis, other reasons such as encephalopathy and especially hyperammonemic encephalopathy (caused by e.g. UCD) should be searched for immediately. However, our result that the majority of newborns with UCD initially present with high blood pressure has to be evaluated in larger patient cohorts.

Keywords: Neonatal urea cycle disorders, Hypertension, Clinical presentation, Hyperammonemic encephalopathy

\section{Background}

The physiologic function of the urea cycle is the irreversible fixation of ammonium $\left(\mathrm{NH}_{4}^{+}\right)$to form water-soluble urea and thus to clear excess nitrogen produced by protein catabolism. Deficiency in one of the six enzymes or two transporters of the urea cycle impairs ureagenesis.

\footnotetext{
* Correspondence: ulrike.teufel@uniklinik-freiburg.de

${ }^{1}$ Center for Child and Adolescent Medicine, Division of Pediatric Neurology and Metabolic Medicine, University Hospital Heidelberg, Heidelberg, Germany

${ }^{2}$ Department of General Pediatrics, Adolescent Medicine and Neonatology, Medical Center, Faculty of Medicine, University of Freiburg, Freiburg, Germany

Full list of author information is available at the end of the article
}

The majority of these diseases results in hyperammonemia leading to rapidly progressing encephalopathy with severe neurologic sequelae or even death. Patients with the most severe neonatal manifestation present with first symptoms after a short symptom-free interval ranging from a few hours to days, while individuals with attenuated late disease onset may present at any age after the newborn period. The overall prevalence of urea cycle disorders (UCD) has been estimated to be approximately 1 in 35,000 for the United States [1] and 1 in 52,000 live births in Germany, Austria and Switzerland [2]. At least half of them present during the newborn period.

(c) The Author(s). 2019 Open Access This article is distributed under the terms of the Creative Commons Attribution 4.0 International License (http://creativecommons.org/licenses/by/4.0/), which permits unrestricted use, distribution, and reproduction in any medium, provided you give appropriate credit to the original author(s) and the source, provide a link to the Creative Commons license, and indicate if changes were made. The Creative Commons Public Domain Dedication waiver (http://creativecommons.org/publicdomain/zero/1.0/) applies to the data made available in this article, unless otherwise stated. 
Newborns with UCD initially present with nonspecific symptoms such as vomiting, feeding refusal, irritability, lethargy, respiratory problems and seizures [35]. Further progress leads to apnea, cerebral edema and death. Emergency care, stabilization of the neonate during acute illness and immediate start of $\mathrm{NH}_{4}{ }^{+}$detoxification are indispensable for survival and for the prevention of irreversible brain damage. The clinical phenotype is often mistaken as neonatal sepsis. Since hyperammonemic encephalopathy of UCD patients shares clinical overlap with other diseases becoming manifest in the newborn period, particularly neonatal sepsis, and hence cannot be reliably identified clinically, diagnosis and start of specific emergency therapy is often delayed.

The aim of this study was to identify clinical parameters that help to distinguish between hyperammonemic encephalopathy and neonatal sepsis and reduce diagnostic and therapeutic delay. Furthermore, we evaluated the impact of diagnostic delay, peak plasma ammonium $\left(\mathrm{NH}_{4}{ }^{+}\right)$concentration, mode of emergency treatment and transfer to a tertiary referral center on the outcome.

\section{Methods}

Seventeen patients, born between 1994 and 2012, with confirmed inherited deficiency of argininosuccinate lyase (ASL; MIM \#207900), argininosuccinate synthetase 1 (ASS1; MIM \#215700), carbamylphosphate synthetase 1 (CPS1; MIM \#237300) or ornithine transcarbamylase (OTC; MIM \#311250) and neonatal hyperammonemic encephalopathy were included. Sixteen of them were transferred to our center for emergency treatment. Information on pregnancy and delivery, onset of symptoms, diagnostic investigations, treatment protocols and outcome were collected from the original medical records of the transferring hospitals and our center.

IBM SPSS 20 for Windows (SPSS INC., Chicago, IL, USA) was used for statistical analyses. Unless stated otherwise, continuous variables are presented as mean \pm standard deviation (SD) and range. The reference values for the age-appropriated 95th percentile of systolic, diastolic and mean arterial blood pressure (MAD) in newborns in the first days of life were based on the values collected by Kent et al. [6, 7]. Differences between groups were tested by Student's $t$ test or, if normality failed, with Kruskal-Wallis or Mann-Whitney U rank-sum test. $P$ values $<0.05$ were regarded as statistically significant in a explorative sense.

The study was performed in accordance with the Declaration of Helsinki of 1975, as revised in 2013 after approval by the ethics committee of the University of Heidelberg, Germany (S-416/2011).

\section{Results}

\section{Study population}

Two patients (one female, one male) with CPS1 deficiency, six (all male) with OTC deficiency, seven (three female, four male) with ASS1 deficiency and two (one female, one male) with ASL deficiency were included in this study. All patients except patient \#15 (ASS1 deficiency), who was identified by newborn screening, were diagnosed after the manifestation of symptoms during the newborn period.

\section{Obstetric history and birth}

All patients were term newborns, except for patient \#6 who was delivered at a gestational age of 36 weeks. Mean gestational age was 39 weeks ( $\mathrm{SD}=1.5$ weeks; range 36 to 41 weeks) and the mean birth weight was $3240 \mathrm{~g}$ (SD = $397 \mathrm{~g}$; range $2685 \mathrm{~g}$ to $4075 \mathrm{~g}$ ). Mean APGAR scores were $8.7(\mathrm{SD}=0.8)$ at $1 \mathrm{~min}, 9.9$ at $5(\mathrm{SD}=0.3)$ and at $10 \mathrm{~min}$ $(\mathrm{SD}=0.2)$. Patients were born by vaginal delivery $(n=12)$ or caesarian section $(n=5$; one primary and four secondary cesarean section).

\section{Clinical presentation and diagnosis}

Table 1 summarizes initial signs and symptoms of the 17 patients. Mean onset of symptoms was at the 4th day of life ( $\mathrm{SD}=1.7$ days; range 2-9 days). Affected newborns most commonly presented with respiratory distress, muscular hypotonia, and lethargy. Seizures were recognized in one patient before admittance. Interestingly, 13 of 16 patients (81\%) presented with increased blood pressure above the 95th percentile before the start of emergency treatment, most of them being lethargic and severely compromised (Fig. 1). Mean systolic, diastolic and MAD pressure was $95 \mathrm{mmHg}, 62.5 \mathrm{mmHg}, 76$ $\mathrm{mmHg}(\mathrm{SD}=15.3$, 13.7, 13.1; range 71-121 mmHg, 50$88 \mathrm{mmHg}, 58-98 \mathrm{mmHg}$ ). Of note, none of the patients received additional intravenous fluid applications including antibiotic therapy before blood pressure measurements. In the 3 newborns with initial normal blood pressure values, the blood pressure remained at the level and did not increase secondary. Even $3 \mathrm{~h}$ after admission to the transferring hospital, 9 of the 13 children with elevated initial blood pressure continued to have elevated blood pressure. Of the remaining four, no blood pressure was documented in three patients at that time and one newborn (\#1) was already intubated. Mean systolic, diastolic and MAD pressure was $100 \mathrm{mmHg}, 71 \mathrm{mmHg}, 86$ $\mathrm{mmHg}(\mathrm{SD}=8.15,12.7,10.9$; range $89-111 \mathrm{mmHg}, 60$ $94 \mathrm{mmHg}, 70-98 \mathrm{mmHg}$ ), respectively. Most children experienced a drop in blood pressure with intubation and associated sedation. Looking at the blood pressure in the individual disease groups, an increase from CPS1 via OTC, ASS to ASL was observed for systolic, diastolic and MAD pressure (Table 2). However, there was no significant difference between systolic $(p=0.4)$ and MAD 
Table 1 Initial clinical presentation and metabolic derangement of neonatal UCD patients

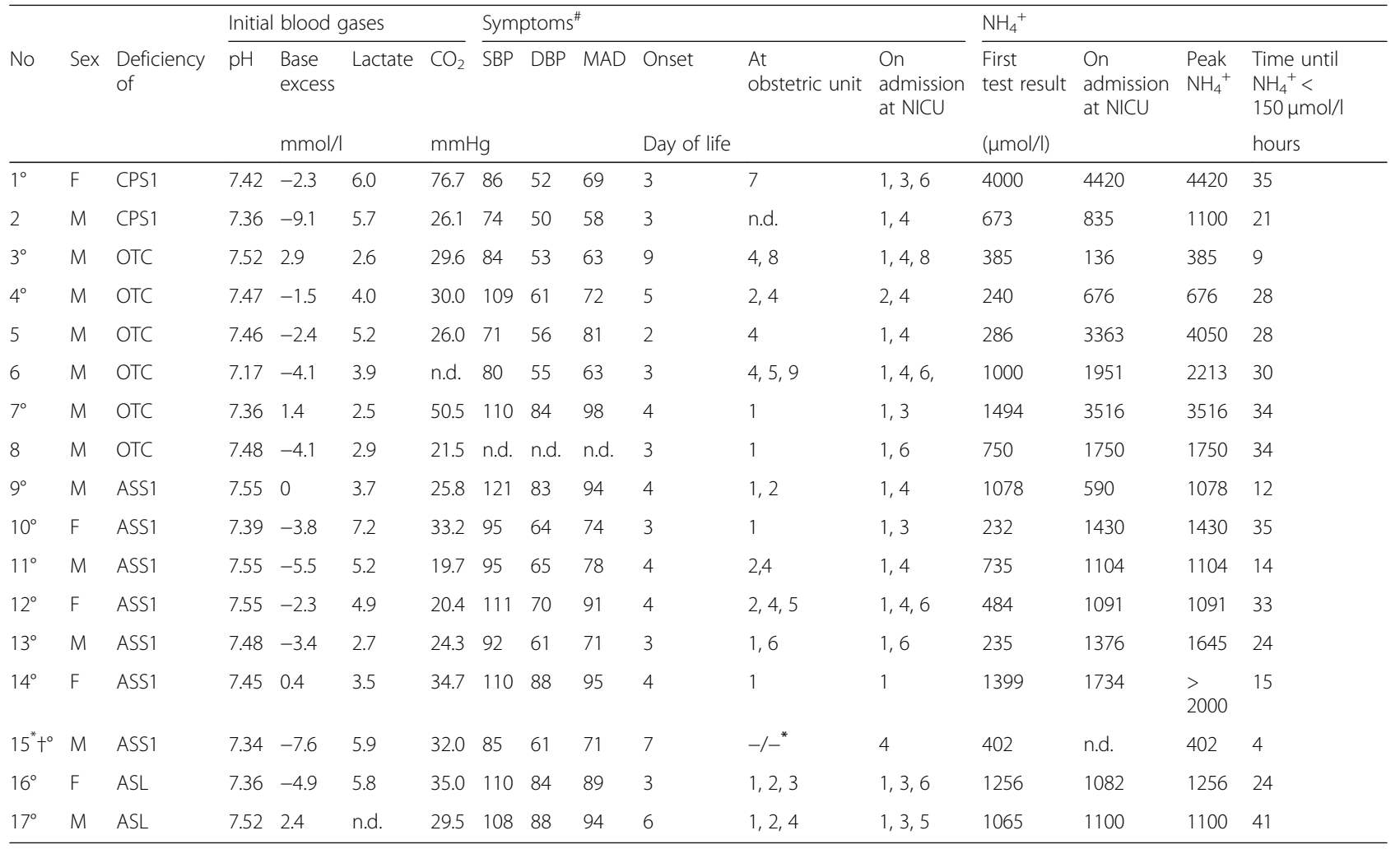

ASL, Argininosuccinate lyase; $A S S 1$, Argininosuccinate synthetase 1; CPS1, Carbamylphosphate synthetase 1; $C O_{2}$, Carbon dioxide; DBP, Diastolic blood pressure; $\mathrm{F}$, Female; $\mathrm{M}$, Male; $\mathrm{NH}_{4}{ }^{+}$, Plasma ammonium concentration; No, Number; $\mathrm{MAD}$, Mean arterial pressure; NICU, Neonatal intensive care unit; $S B P$, Systolic blood pressure; OTC, Ornithine transcarbamylase deficiency;

\#Symptoms: 1: respiratory distress, 2: poor feeding, feeding difficulties, 3: muscular hypertonia, 4: lethargy/ muscular hypotonia, 5: hypothermia, 6: acrocyanosis, 7: seizures, 8: vomiting, 9: hypoglycemia

${ }^{\circ}=$ blood pressure above the 95 th percentile ${ }^{*}=$ identified by newborn screening, $\dagger=$ not transferred to our centre; $n . d .=$ not documented,

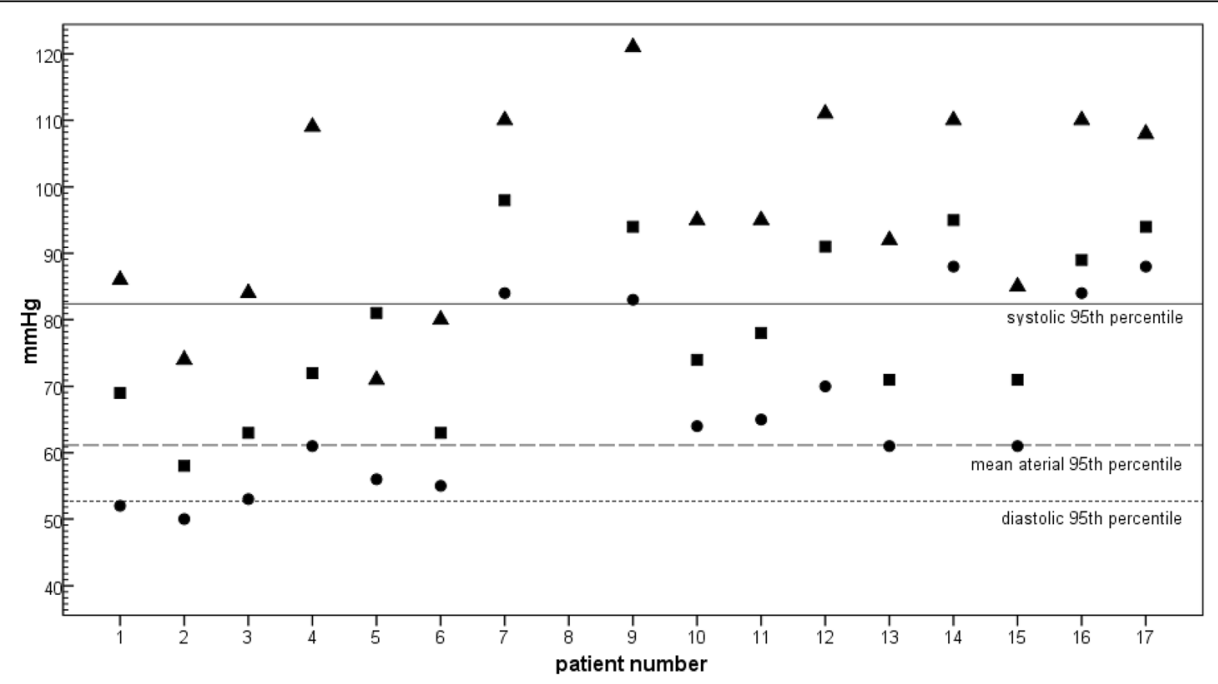

Fig. 1 Initial systolic, diastolic and mean arterial blood pressure of the newborns with the respective 95th percentile. Legend: $\mathbf{\Delta}$ systolic blood pressure; mean aterial blood pressure; $\bullet$ diastolic blood pressure 
Table 2 Mean blood pressure, mean initial ammonium level in transferring hospital and at admittance to NICU subdivided by UCD enzyme deficiency

\begin{tabular}{|c|c|c|c|c|c|}
\hline \multirow[t]{2}{*}{ Deficiency of } & \multicolumn{3}{|c|}{ Blood pressure $(\mathrm{mmHg})$} & \multicolumn{2}{|l|}{$\mathrm{NH}_{4}^{+}(\mu \mathrm{mol} / \mathrm{l})$} \\
\hline & $\mathrm{SBP}$ & DBP & MAD & First test result & On Admission at NICU \\
\hline$\overline{\mathrm{CPS} 1}$ & 80 & 51 & 64 & 2376 & 2628 \\
\hline OTC & 84 & 56 & 72 & 568 & 1851 \\
\hline ASS1 & 95 & 65 & 78 & 484 & 1240 \\
\hline ASL & 109 & 86 & 92 & 1160 & 1091 \\
\hline
\end{tabular}

$A S L$, Argininosuccinate lyase; $A S S 1$, Argininosuccinate synthetase 1; CPS1, Carbamylphosphate synthetase 1; $D B P$, Diastolic blood pressure; $\mathrm{NH}_{4}{ }^{+}, \mathrm{Plasma}$ ammonium concentration; No, Number; MAD, Mean arterial pressure; NICU, Neonatal intensive care unit; SBP, Systolic blood pressure; OTC, Ornithine transcarbamylase deficiency;

pressure $(p=0.21)$ for each individual disease. Only with diastolic pressure a significance $(p=0.038)$ was detected between CPS1 and ASL. In one patient, initial blood pressure was not reported. In all patients, neonatal sepsis was initially suspected, but was not confirmed in any. With the exception of patient (\#1), who was immediately intubated in the referring clinic, none of the newborns initially received a volume bolus.

In the initial work-up, all patients received cranial ultrasound, 14 of them echocardiography and eight abdominal ultrasound. Thorathic X-rays were performed in 13 patients, while eight patients received a lumbar puncture during the work-up of neonatal sepsis. Twelve received intubation and mechanical ventilation due to respiratory distress. One newborn (\#1) was intubated immediately after admission to the transferring hospital. The other eleven were intubated before the transfer to our center. Two patients required catecholamines after intubation and eight of them a central venous catheter.

Laboratory tests focusing on parameters of neonatal sepsis (blood count and c-reactive protein (CRP)) were obtained within two hours. Twelve patients received antibiotics immediately after initial blood samples were taken at the transferring pediatric hospital. The antibiotic therapy varied according to the individual standard procedures. Six newborns received antibiotic triple therapy with ampicillin, cephalosporin plus an aminoglycoside. Three newborns obtained ampicillin and aminoglycoside, one received ampicillin plus cephalosporine, one got cephalosporine and glycopeptides and one received only cephalosporine. Blood gases (Table 1) were determined in all patients showing means for $\mathrm{pH}$ of 7.46 $(\mathrm{SD}=0.1$; range 7.17-7.55), base excess $(\mathrm{BE})-2.4(\mathrm{SD}=$ 3.2 ; range $-9.1-2.9)$ and carbon dioxide $\left(\mathrm{CO}_{2}\right)$ of 29.6 $\mathrm{mmHg}(\mathrm{SD}=13.6 \mathrm{mmHg}$; range $19.7-76.7 \mathrm{mmHg}$ ). In our population, respiratory alkalosis at initial presentation was present in 11 patients $(65 \%)$. One patient (\#1) with respiratory insufficiency and thus elevated $\mathrm{CO}_{2}$ $(76.7 \mathrm{mmHg})$ was intubated immediately after admittance to the referring hospital. Plasma $\mathrm{NH}_{4}{ }^{+}$concentrations were determined with a mean delay of $3 \mathrm{~h}$ after admission to a Pediatric Department $(S D=11.5$ h; range
1-41 h; except for \#15 who was identified by newborn screening). Mean initial $\mathrm{NH}_{4}^{+}$concentration was $735 \mu \mathrm{mol} / \mathrm{l}(\mathrm{SD}=897 \mu \mathrm{mol} / \mathrm{l}$, range $232-4000 \mu \mathrm{mol} / \mathrm{l})$. In all patients first therapeutic measures following suspicion of a UCD were transient stop of protein intake and intravenous application of glucose $(15-20 \mathrm{~g} / \mathrm{kg} / \mathrm{d}$, with or without insulin). Two patients (\#1 and \#2) received no additional metabolic therapy until in-patient admission in our center. Five patients received intravenous application of only arginine hydrochloride (\#7, \#8, \#10, $\# 14$, \#18), one patient (\#11) only intravenous sodium benzoate and nine patients both medications. Eight patients received L-carnitine.

\section{Progress after transferal}

Overall 16 UCD patients (except \#15) from 14 different hospitals were transferred to the neonatal intensive care unit (NICU) of our center after a mean time interval of 1.1 days ( $\mathrm{SD}=1.1$ days; range $0-4$ days) following the start of symptoms. Although emergency therapy was started in the referring hospitals, mean plasma $\mathrm{NH}_{4}{ }^{+}$concentrations further increased from $735 \mu \mathrm{mol} / \mathrm{l}(\mathrm{SD}=897 \mu \mathrm{mol} / \mathrm{l}$; range $232-4000 \mu \mathrm{mol} / \mathrm{l}) \quad$ to $1240 \mu \mathrm{mol} / \mathrm{l} \quad(\mathrm{SD}=1171 \mu \mathrm{mol} / \mathrm{l}$; range $136-4420 \mu \mathrm{mol} / \mathrm{l})$ at arrival in our center and three patients required immediate intubation and mechanic ventilation due to respiratory insufficiency. Although intravenous emergency treatment with high glucose, arginine hydrochloride and sodium benzoate was intensified, plasma $\mathrm{NH}_{4}{ }^{+}$concentrations increased further in five patients before extracorporeal detoxification was started. Mean maximum $\mathrm{NH}_{4}{ }^{+}$concentration was $1537 \mu \mathrm{mol} / \mathrm{l}$ $(\mathrm{SD}=1238 \mu \mathrm{mol} / \mathrm{l}$; range $385-4420 \mu \mathrm{mol} / \mathrm{l})$. Looking at $\mathrm{NH}_{4}{ }^{+}$concentrations in the individual disease groups there was no significant difference between mean initial $\mathrm{NH}_{4}{ }^{+}$concentrations $(p=0.68)$ and on admittance at NICU $(p=0.74)$ (Table 2).

Extracorporeal detoxification with hemodialysis/hemofiltration via central venous Shaldon catheter was performed in 15 UCD patients. Mean time interval between admission to our center and start of hemodialysis/hemofiltration was $3.3 \mathrm{~h}(\mathrm{SD}=1.4 \mathrm{~h}$, range $0.4-5.5 \mathrm{~h})$. A mean duration of $24.8 \mathrm{~h}$ (SD $10.4 \mathrm{~h}$, range $4-41 \mathrm{~h}$ ) was 
required to reduce plasma $\mathrm{NH}_{4}{ }^{+}$concentrations to below $150 \mu \mathrm{mol} / \mathrm{l}$. Hemodialysis/hemofiltration was continued for a mean of $23.5 \mathrm{~h}(\mathrm{SD}=14.8 \mathrm{~h}$; range $1.5-52$ h). In six patients, plasma $\mathrm{NH}_{4}{ }^{+}$concentrations increased again after discontinuation of extracorporeal detoxification. In one patient, hemodialysis/hemofiltration had to be started a second time.

Hypothermia was started in five patients. In analogy to standard protocols for hypothermia treatment in asphyxiated newborns, patients were cooled to $33.5^{\circ} \mathrm{C}$ for $72 \mathrm{~h}$ using Hico Variotherm 550 (Hirtz). No severe side effects like coagulopathy were observed during hypothermia. After $72 \mathrm{~h}$ body temperature was increased by $0.5^{\circ} \mathrm{C}$ per hour until a body temperature of $37^{\circ} \mathrm{C}$ was reached.

During NICU management three patients required resuscitation. Two patients developed a hypovolemic shock, one (\#14) after bleeding from the umbilical vein five days after insertion of the Shaldon catheter, and one (\#16) due to high fluid removal during hemodialysis. In the course of resuscitation the latter patient developed a pneumothorax. The third patient (\#1) had cardiac arrest following an episode of supraventricular tachycardia.

In patients $\# 5,7$ and 8, therapy was discontinued in the next days to come in agreement with their parents due to an extremely low protein tolerance which was much below minimal requirements for dietary treatment. All of them had severe brain damage which was also confirmed by MRI. They died 7.1 h (mean; SD = 7.1; range 2.25-16.5) after discontinuation of intensive care and metabolic therapy.

Eleven of the surviving patients have been regularly followed by our outpatient clinic until now (mean age: 12 years, $\mathrm{SD}=5.1$ years; range 2.4-19.9). Apart from \#3 and \#9 all showed impairments of intellectual and motor functions. Both have in common that there was no further increase until the admission in our center, but even a halving of the initial $\mathrm{NH}_{4}{ }^{+}$concentration. But all other values such as the time of the first $\mathrm{NH}_{4}{ }^{+}$concentration, metabolic emergency therapy, need for ventilation or dialysis differ.

\section{Discussion}

Hyperammonemic encephalopathy in newborns with UCDs is a life-threatening metabolic emergency that requires immediate and targeted treatment to prevent irreversible brain damage and death. The diagnosis of UCDs is often delayed, since clinical presentation shows broad overlap with other neonatal emergencies, in particular neonatal sepsis. The major aim of this study is to better distinguish neonatal onset of UCDs from the more frequent neonatal sepsis. The clinical presentation of UCD patients in this study is in line with previous reports on neonatal onset of UCD patients [3-5]: Progressive respiratory distress, muscular hypotonia and lethargy were the most frequent clinical symptoms. Striking and not previously reported was the finding of high blood pressure during hyperammonemic encephalopathy, a finding clearly distinguishing between UCDs and neonatal sepsis. Blood pressure was determined by oscillometry. Even in pediatric population oscillometric and radial artery blood pressure are closely correlated with only a small error [8]. In contrast to preterm infants there is no correlation between blood pressure and birth weight, length or gestational age in term infants $[6,7,9]$. In our cohort except one all were term infants. As described above 13 out of 16 patients $(81 \%)$ in our study had a blood pressure above the age-appropriate 95th percentile [6] at first contact with a pediatrician due to clinical worsening, with most neonates being lethargic and severely compromised. Therefore high blood pressure was not due to increased activity or additional fluid administration. Beside activity an alternative cause of neonatal hypertension is increased intracranial pressure due to cerebral edema [10]. The initial cranial ultrasound including Doppler and Power color Doppler examination, however, showed no evidence for an apparent brain edema on admittance. Alternatively, low plasma arginine concentrations, which are characteristic for urea cycle disorders, can also be a reason for arterial hypertension. Production of arginine is important for endogenous cellular production of nitric oxide (NO), a potent vasodilator [11]. Patients with UCD, except those with arginase 1 deficiency, have low arginine levels. In ASL deficiency impaired systemic NO production is thought to rely on disturbed formation of a complex including ASL and endothelial NO synthase among other components [12]. In a newborn receiving arginine for evaluation of pituitary function a drop of blood pressure was seen after infusion of arginine followed by re-rising after discontinuation [13]. Nelin et al. [14] showed that arginine infusion lowers blood pressure in normotensive infants. A few cases reported about children with ASL deficiency and arterial hypertension. Arterial hypertension was resolved with intravenous infusion of arginine [13, 15]. We aimed to test this hypothesis in our study population, however, plasma arginine concentrations were determined only in 5 of the 17 patients before starting metabolic emergency treatment which also includes arginine. In addition, we were able to show that the initial high blood pressure is not a one-off event, but initially persisted in newborns with UCD. For most of them, sedation and intubation led to a drop in blood pressure. Since in neonatal sepsis and other causes of severe disease systemic blood pressure is mostly reduced [16], elevated blood pressure, probably readily explained by the pathophysiology of UCD, may be an important indicator for UCD. 
Blood gases are often the first quantitative data available in a very sick infant. Since respiratory alkalosis was present in $65 \%$ of patients at initial presentation, this finding should be considered as another indicator of UCDs in any rapidly deteriorating neonate $[5,17]$.

Three out of the 17 patients died in the course of their first crisis. All others stayed alive, and 11 patients are still followed regularly in our outpatient clinics (mean follow-up time 13.6 years, $\mathrm{SD}=5.5$ years). Only two of the 11 surviving patients (\#3: peak plasma $\mathrm{NH}_{4}{ }^{+}$concentrations: $590 \mu \mathrm{mol} / \mathrm{l}$ and \#9: $385 \mu \mathrm{mol} / \mathrm{l})$ are not cognitively disabled. Their favorable neurological outcome may be due to only moderate peak plasma $\mathrm{NH}_{4}{ }^{+}$concentrations during the neonatal crisis. In addition to age at disease onset the initial peak plasma $\mathrm{NH}_{4}{ }^{+}$concentration is an important predictor of the neurological outcome $[18,19]$. In a cohort of 456 patients, Posset et al. [18] described an initial peak $\mathrm{NH}_{4}{ }^{+}$above $500 \mu \mathrm{mol} / \mathrm{l}$ to be associated with neurological impairment. In 88 patients with UCDs reported by Bachmann et al. [19] none of the patients with an initial $\mathrm{NH}_{4}{ }^{+}$level above $300 \mu \mathrm{mol} / \mathrm{l}$ (first test result) or $480 \mu \mathrm{mol} / \mathrm{l}$ (peak) achieved a normal neurological outcome. This has been confirmed by other studies [20, 21]. In our population we noticed no significant differences of plasma $\mathrm{NH}_{4}{ }^{+}$ concentrations between specific UCDs, whereby number of patients was small. Early diagnosis and immediate start of metabolic therapy aiming to normalize plasma $\mathrm{NH}_{4}{ }^{+}$concentrations is the prerequisite to prevent irreversible brain damage [22]. Noteworthy, until extracorporeal detoxification was started, plasma $\mathrm{NH}_{4}{ }^{+}$ concentrations further increased in the majority of patients despite intensified intravenous therapy with sodium benzoate, arginine and high-dose glucose therapy in combination with insulin. This highlights that intravenous emergency treatment is often insufficient to lower plasma $\mathrm{NH}_{4}{ }^{+}$concentrations rapidly and reliably and therefore hemodialysis has to be considered early. From this it can be concluded that a timely transport of every patient with hyperammonemic encephalopathy to a metabolic center which operates hemodialysis in neonates should be considered, planned and organized.

Five patients were treated with hypothermia in addition to pharmacologic and extracorporeal detoxification. This potentially neuroprotective intervention has been described in animal experiments and small clinical trials in hepatic encephalopathy. One of the protective effects of hypothermia may be the prevention of osmolyte depletion in the brain. In astrocytes, $\mathrm{NH}_{4}{ }^{+}$is reversibly fixed to glutamate forming. The $\mathrm{NH}_{4}{ }^{+}$/glutamine/ brain swelling hypothesis of hepatic encephalopathy suggests that accumulation of glutamine causes astrocytes to swell [23]. Decreased $\mathrm{NH}_{4}{ }^{+}$delivery to the brain when patients with acute liver failure were cooled was referred to by Jalan [24, 25]. Polderman [26] reported a reduction of the metabolic rate by $8 \%$ per degree Celsius. There is one study reporting first results about feasibility of therapeutic hypothermia in neonatal hyperammonemia due to UCD [27].

\section{Conclusion}

Unfortunately the diagnosis of UCDs is often delayed [28]. Therefore it is most important to further increase the awareness for UCDs as a differential diagnosis in acutely ill neonates. Until now respiratory alkalosis had been recognized as an easily detectable, but inconsistent initial finding of UCDs [29]. Our study confirms this previous observation and highlights for the first time that elevated blood pressure might be an even better indicator of UCDs in newborns and distinguishes it from more frequent neonatal sepsis. Blood gases, blood pressure and plasma $\mathrm{NH}_{4}{ }^{+}$should be determined without delay in every sick neonate with suspected neonatal sepsis.

\section{Abbreviations}

ASL: Argininosuccinate lyase deficiency; ASS1: Argininosuccinate synthetase 1 deficiency; BE: Base excess; $\mathrm{CO}_{2}$ : Carbon dioxide; CPS1: Carbamylphosphate synthetase 1 deficiency; CRP: C-reactive protein; e.g: for example; g: gram; MAD: mean arterial blood pressure; mg: milligram; MRI: magnetic resonance imaging; n: number; $\mathrm{NH}_{4}^{+}$: ammonium; NICU: Neonatal intensive care unit; NO: Nitric oxide; OTC: Ornithine transcarbamylase deficiency; SD: Standard deviation; UCD: urea cycle disorders

\section{Acknowledgements}

We would like to thank all families, referring colleagues and hospitals.

Funding

No funding.

\section{Availability of data and materials}

The datasets generated and analysed during the current study are not publicly available due to data privacy reasons but are available from the corresponding author upon reasonable request.

\section{Authors' contributions}

UT collected data, drafted the initial and wrote the final manuscript as submitted. PB undertook the statistical analysis and revised the final manuscript. JM managed ICU therapy and contributed to the final manuscript. ML managed metabolic ICU therapy and critically reviewed the final manuscript. JP designed the study and revised the final manuscript. GFH designed the study and critically reviewed and revised the final manuscript. SK managed metabolic ICU therapy, reviewed the manuscript and revised the final manuscript. PR supervised data collection, undertook the statistical analysis and revised the final manuscript.

\section{Ethics approval and consent to participate}

The study was approved by the ethics committee of the University of Heidelberg, Germany (S-416/2011).

\section{Consent for publication}

Not applicable.

\section{Competing interests}

UT reports non-financial support from MSD Sharp\& Dome, non-financial support from AbbVie, outside the submitted work. PB reports lecture fees from Nutrica, vitaflo, Recordati, and Dr. Schär, and a grant from vitaflo. JM reports grants from Cytonet $\mathrm{GmbH}$, Commercial Sponsor, during the conduct of the study. ML reports grants from Cytonet $\mathrm{GmbH}$, Commercial Sponsor, during 
the conduct of the study; personal fees from Orphan Europe Nutricia, others, outside the submitted work. JP reports no competing interests. GFH reports grants from Cytonet $\mathrm{GmbH}$, Commercial Sponsor, during the conduct of the study, grants from the Dietmar Hopp Foundation (St. Leon-Rot, Germany), as well as lecture fees from Sobi. PR reports no competing interests. SK reports grants from the European Commission (Chafea grant agreement no. 201012 01; for the project E-IMD), Dietmar Hopp Foundation (St. Leon-Rot, Germany), Kindness for Kids Foundation (Munich, Germany) and Horizon Pharma Ireland Limited (RRPE, study number HPZN-RAV-401).

\section{Publisher's Note}

Springer Nature remains neutral with regard to jurisdictional claims in published maps and institutional affiliations.

\section{Author details \\ ${ }^{1}$ Center for Child and Adolescent Medicine, Division of Pediatric Neurology and Metabolic Medicine, University Hospital Heidelberg, Heidelberg, Germany. ${ }^{2}$ Department of General Pediatrics, Adolescent Medicine and Neonatology, Medical Center, Faculty of Medicine, University of Freiburg, Freiburg, Germany. ${ }^{3}$ University Children's Hospital Frankfurt, Frankfurt, Germany. ${ }^{4}$ Department of Pediatrics, Clinic of Neonatology, University of Heidelberg, Heidelberg, Germany. ${ }^{5}$ Department of Pediatrics, SLK-Kliniken Heilbronn GmbH, Heilbronn, Germany.}

\section{Received: 8 December 2018 Accepted: 1 April 2019}

Published online: 08 April 2019

\section{References}

1. Summar ML, Koelker S, Freedenberg D, et al. European registry and network for intoxication type metabolic diseases (E-IMD): the incidence of urea cycle disorders. Mol Genet Metab. 2013;110:179-80.

2. Nettesheim S, Kölker S, Karall D, Häberle J, Posset R, Hoffmann GF, Heinrich B, Gleich F, Garbade SF. Arbeitsgemeinschaft für Pädiatrische Stoffwechselstörungen (APS); European registry and network for intoxication type metabolic diseases (E-IMD); Erhebungseinheit für Seltene Pädiatrische Erkrankungen in Deutschland (ESPED); Austrian metabolic group; Swiss Paediatric surveillance unit (SPSU). Incidence, disease onset and short-term outcome in urea cycle disorders -cross-border surveillance in Germany, Austria and Switzerland. Orphanet J Rare Dis. 2017;12:111.

3. Kölker S, Garcia-Cazorla A, Valayannopoulos V, Lund AM, Burlina AB, SykutCegielska J, Wijburg FA, Teles EL, Zeman J, Dionisi-Vici C, Barić I, Karall D, Augoustides-Savvopoulou P, Aksglaede L, Arnoux JB, Avram P, Baumgartner MR, Blasco-Alonso J, Chabrol B, Chakrapani A, Chapman K, I Saladelafont EC, Couce ML, de Meirleir L, Dobbelaere D, Dvorakova V, Furlan F, Gleich F, Gradowska W, Grünewald S, Jalan A, Häberle J, Haege G, Lachmann R, Laemmle A, Langereis $E$, de Lonlay $P$, Martinelli $D$, Matsumoto $S$, Mühlhausen C, de Baulny HO, Ortez C, Peña-Quintana L, Ramadža DP, Rodrigues E, Scholl-Bürgi S, Sokal E, Staufner C, Summar ML, Thompson N, Vara R, Pinera IV, Walter JH, Williams M, Burgard P. The phenotypic spectrum of organic acidurias and urea cycle disorders. Part 1: the initial presentation. J Inherit Metab Dis. 2015;38:1041-57.

4. Gardeitchik T, Humphrey M, Nation J, et al. Early clinical manifestations and eating patterns in patients with urea cycle disorders. J Pediatr. 2012;161: 328-32

5. Maestri NE, Clissold D, Brusilow SW. Neonatal onset ornithine transcarbamylase deficiency: a retrospective analysis. J Pediatr. 1999;134: 268-72.

6. Kent AL, Kecskes Z, Shadbolt B, et al. Normative blood pressure data in the early neonatal period. Pediatr Nephrol. 2007;22:1335-41.

7. Kent AL, Kecskes Z, Shadbolt B, et al. Blood pressure in the first year of life in healthy infants born at term. Pediatr Nephrol. 2007;22:1743-9.

8. Park MK, Menard SM. Accuracy of blood pressure measurement by the Dinamap monitor in infants and children. Pediatrics. 1987;79:907-14.

9. Pejovic B, Peco-Antic A, Marinkovic-Eric J. Blood pressure in non-critically ill preterm and full-term neonates. Pediatr Nephrol. 2007;22:249-57.

10. Dionne JM, Abitbol CL, Flynn JT. Hypertension in infancy: diagnosis, management and outcome. Pediatr Nephrol. 2012;27:17-32.

11. Palmer RM, Ashton DS, Moncada S. Vascular endothelial cells synthesize nitric oxide from L-arginine. Nature. 1988;333:664-6.
12. Erez A, Nagamani SC, Shchelochkov OA, et al. Requirement of argininosuccinate lyase for systemic nitric oxide production. Nat Med. 2011;17:1619-26.

13. Fakler CR, Kaftan HA, Nelin LD. Two cases suggesting a role for the Larginine nitric oxide pathway in neonatal blood pressure regulation. Acta Paediatr. 1995:84:460-2.

14. Nelin LD, Hoffmann GM. L-arginine infusion lowers blood pressure in children. J Pediatr. 2001;139:747-9.

15. Brunetti-Pierri N, Erez A, Shchelochkov O, Craigen W, Lee B. Systemic hypertension in two patients with ASL deficiency: a result of nitric oxide deficiency? Mol Genet Metab. 2009;98:195-7.

16. Giesinger RE, McNamara PJ. Hemodynamic instability in the critically ill neonate: an approach to cardiovascular support based on disease pathophysiology. Semin Perinatol. 2016;40:174-88.

17. Nassogne MC, Héron B, Touati G, Rabier D, Saudubray JM. Urea cycle defects: management and outcome. J Inherit Metab Dis. 2005;28:407-14.

18. Posset R, Garcia-Cazorla A, Valayannopoulos V, Teles EL, Dionisi-Vici C, Brassier A, Burlina AB, Burgard P, Cortès-Saladelafont E, Dobbelaere D, Couce ML, Sykut-Cegielska J, Häberle J, Lund AM, Chakrapani A, Schiff M, Walter JH, Zeman J, Vara R, Kölker S. Additional individual contributors of the E-IMD consortium. Age at disease onset and peak ammonium level rather than interventional variables predict the neurological outcome in urea cycle disorders. J Inherit Metab Dis. 2016;39:661-72.

19. Bachmann C. Long-term outcome of patients with urea cycle disorders and the question of neonatal screening. Eur J Pediatr. 2003;162:Suppl 1:29-33.

20. Msall M, Batshaw ML, Suss R, et al. Neurologic outcome in children with inborn errors of urea synthesis. Outcome of urea-cycle enzymopathies. $\mathrm{N}$ Engl J Med. 1984;310:1500-5.

21. Uchino T, Endo F, Matsuda I. Neurodevelopmental outcome of long-term therapy of urea cycle disorders in Japan. J Inherit Metab Dis. 1998;21(Suppl 1):151-9.

22. Bachmann C. Outcome and survival of 88 patients with urea cycle disorders: a retrospective evaluation. Eur J Pediatr. 2003;162:410-6.

23. Häussinger D, Kircheis G, Fischer R, et al. Hepatic encephalopathy in chronic liver disease: a clinical manifestation of astrocyte swelling and low-grade cerebral edema? J Hepatol. 2000;32:1035-8.

24. Jalan $\mathrm{R}$, Olde Damink SW, Deutz NE, et al. Moderate hypothermia in patients with acute liver failure and uncontrolled intracranial hypertension. Gastroenterology. 2004;127:1338-46.

25. Jalan R, O Damink SW, Deutz NE, et al. Moderate hypothermia for uncontrolled intracranial hypertension in acute liver failure. Lancet. 1999; 354:1164-8.

26. Polderman $\mathrm{KH}$. Mechanisms of action, physiological effects, and complications of hypothermia. Crit Care Med. 2009:37(Suppl 1):186-202.

27. Lichter-Konecki U, Nadkarni V, Moudgil A, et al. Feasibility of adjunct therapeutic hypothermia treatment for hyperammonemia and encephalopathy due to urea cycle disorders and organic acidemias. Mol Genet Metab. 2013:109:354-9.

28. Summar M, Tuchman M. Proceedings of a consensus conference for the management of patients with urea cycle disorders. J Pediatr. 2001;138(Suppl 1):6-10.

29. Kölker S, Garcia-Cazorla A, Vallayannopoulos V, et al. The phenotypic spectrum of organic acidurias and urea cycle disorders. Part 1: the initial presentation. J Inherit Metab Dis. 2015;38:1041-57.

Ready to submit your research? Choose BMC and benefit from:

- fast, convenient online submission

- thorough peer review by experienced researchers in your field

- rapid publication on acceptance

- support for research data, including large and complex data types

- gold Open Access which fosters wider collaboration and increased citations

- maximum visibility for your research: over $100 \mathrm{M}$ website views per year

At $\mathrm{BMC}$, research is always in progress.

Learn more biomedcentral.com/submissions 